\title{
Business Students' Views of Peer Assessment on Class Participation
}

\author{
Fidella Tiew \\ School of Business, Curtin University of Technology \\ Sarawak Campus, 98009 Miri, Sarawak, Malaysia \\ Tel: 60-85-443-939Ｅ-mail: fidella.t@curtin.edu.my
}

\begin{abstract}
The purpose of this project was to introduce peer and self assessment on tutorial class participation to a marketing unit at Curtin Sarawak. This assessment strategy was introduced with desire to improve class participation and increase student involvement in assessment. At the end of semester, a questionnaire was used to gather responses from a sample of 77 students about their opinions on the peer assessment practice. Students agreed that the practice promotes a sense of ownership, engagement and personal responsibility of the learning experience. But at the same time, many experienced some stress in the assessment process and found it not easy to evaluate their peers. The study found students do not reject peer assessment strategy.
\end{abstract}

Keywords: Class participation, Peer assessment, Business student, Curtin Sarawak.

\section{Introduction}

Despite the universal advice against grading class participation from assessment and measurement scholars (Davis, 1993), class participation remains an important item of student evaluation in business courses, especially where case discussions are an integral part of the course. A study of core curriculum syllabi at Seattle University discovered that 93 percent of courses included class participation as a component of course grades (Bean \& Peterson, 1998). At Curtin University of Technology, Sarawak Campus, more than half of business programs building participation into course grading. Normally it constitutes a relatively small proportion of the course grade ranging from 5 percent to 20 percent. Majority of business students study at this campus are local Malaysians. Knowing the background of these students, many come from education systems where students are passive learners and they are not encouraged to speak up or ask question in class, it is a challenge for these students to participate actively in classroom discussion. The personality of some also inhibits them from speaking up in class, leading them to feel stressed to have this method of assessment.

Assigning a class participation mark is very complicated because of its subjective nature. Several evaluation tools have been published to assist teachers in assessing class participation (Bean \& Peterson, 1998; Chapnick, 2009; Craven \& Hogan, 2001; Maznevski 1996; Melvin, 1988). The use of published scales may assist in the process, but assigning a class participation grade remains difficult to objectify. The equivocal nature of evaluating class participation makes it an ideal area in which to share evaluation with students. Multiple evaluators may increase the accuracy of class participation grading. Student involvement in assessment typically takes the form of peer or self assessment. As research suggests, peer and self-assessment has been increasingly used as an alternative method of engaging students in the development of their own learning. It encourages for example student autonomy and higher order thinking skills, whilst in contrast potential weaknesses can be minimized with anonymity, multiple assessors and moderation by tutors (Van Den Berg, 2006).

A quick email survey indicated that peer assessment on class participation is a rare practice in the School of Business at Curtin Sarawak. The use of peer assessments is confined to assessing students' oral presentation and contribution to group work, which is mainly conducted in management and marketing courses only. Thus, the purpose of this project was to introduce peer and self assessment on tutorial class participation and to collate information on students' opinions of this assessment process.

\section{Literature review}

Class participation promotes active learning, critical thinking, development of listening and speaking skills needed for career success, and the ability to join a discipline's conversation (Bean \& Peterson, 1998). When students see that their participation is being graded regularly and consistently, they adjust their study habits accordingly so as to be well prepared for active class participation.

To grade class participation fairly, the lecturer needs to create an environment that gives all students an opportunity to participate. According to Bean and Peterson (1998), the most common participatory classroom uses open or whole-class discussion, wherein the lecturer poses questions aimed at drawing all class members into conversation. Another is the "cold-calling" mode, where the lecturers poses a question and then calls on 
students at random to formulate their answers. Still another kind of participatory class employs collaborative learning, in which students work in small groups toward a consensus solution of problems designed by the lecturer and then report their solutions in a plenary session.

According to Topping (2009), peer assessment is an arrangement for learners to consider and specify the level, value, or quality of a product or performance of other equal-status learners. In simple terms, it is students grading the work or performance of their peers using relevant criteria (Falchikov, 2001).

The use of peer assessment in higher education has been advocated by many academics (for example Stefani, 1994; Boud, 1995; Topping, 1998 \& 2009; Falchikov \& Goldfinch, 2000; Sivan, 2000). The method has been tried out at different levels, across disciplines and with different types of assignments including writing, portfolios, oral presentations, test performance, and other skilled behaviors (Topping, 2009). The use of peer evaluation of class participation has also been previously reported (Bean \& Peterson, 1998; Gopinath, 1999; Melvin, 1988; Ryan et al., 2007).

There is substantial evidence that peer assessment can result in improvements in the effectiveness and quality of learning, with gains for assessors, assessees, or both (Topping, 2009). Peer assessment involves students directly in learning, thus promoting a sense of autonomy and ownership of the assessment process which improves motivation. Peer assessments can lead teachers to scrutinize and clarify assessment objectives and purposes; criteria and grading scales.

On the other hand, peer assessment process can cause anxiety to both assessors and assessees. Social processes can influence and contaminate the reliability and validity of peer assessments. Peer assessments can be partly determined by friendship bonds, enmity, or other power processes, the popularity of individuals, perception of criticism as socially uncomfortable, or even collusion to submit average scores, leading to lack of differentiation (Topping, 2009).

The validity and reliability of peer evaluations is debatable. Over $70 \%$ of the studies find reliability and validity adequate (Sadler \& Good, 2006); a minority find them variable (Falchikov \& Goldfinch, 2000; Topping, 1998). Literature review regarding self and peer-assessment shows, in general students tend to overrate themselves. A tendency for peer marks to bunch around the median is sometimes noted. Student acceptance varies from high to low. Contradictory findings can be explained in part by differences in contexts, the level of the course, the product or performance being evaluated, the contingencies associated with those outcomes, clarity of judgment criteria, and the training and support provided (Topping, 2009).

\section{Method}

The study consisted of two cycles of action research which involves business students enrolled in Services Marketing unit over two semester periods in 2009. Forty-two and thirty-five students enrolled in Semester 1 and 2 respectively. Each semester has two tutorial groups. These students were either in their second or third year of studies at the Business School, Curtin Sarawak. Tutorial participation contributes ten percent to the final grade of the unit. Though it is a relatively small proportion of the unit grade, yet it is large enough to motivate students to attend and participate in weekly tutorial discussions. Each tutorial group met once per week for one and half hours throughout a 12 -week semester.

During the first session in both cycles of the action research, students were informed of the nature and process of peer assessment, clarify rationale and expectations. This was part of the subject induction. Students were given the opportunity to voice their opinions and ask questions on the assessment. In the first cycle the criteria for assessment were provided by the lecturer but in the second cycle the criteria were established by the students. As suggested by Topping (2009, p.25), involving students in developing the criteria for assessment promotes a sense of ownership and decreases student anxiety. Following the lecturer's introduction of the methodology, students are asked to suggest criteria for assessing their fellow students. They started with brainstorming in small groups followed by a presentation of the criteria accepted by each group. To arrive at an agreed set of criteria, a discussion was facilitated by the lecturer to examine the meaning of each criterion, its use and relevance. Based on the agreed list of criteria, the lecturer developed an assessment rubric for class participation.

Students received the rubric (assessment form) on week 2 together with a complete student list. A short training to show students how to do peer assessment was conducted. The problem of impressionism in assessing classroom participation can be substantially alleviated through a scoring rubric. Using such a rubric, points for class discussion were assigned at three different times in the twelve-week semester (weeks 4, 7 and 10). With regularly assigned points, students had the opportunity to evaluate and improve their performance, thus making the final class participation mark less arbitrary. Feedback and coaching were given where needed. 
Each student has to assess everyone in the class including themselves. In every tutorial session, students were asked to put their names on their desk for identification purpose. Each week there was pre-assigned readings, case studies or open-ended assignments given to the student. Throughout the semester, student participation was evaluated during whole-class discussions, small group presentations, question and answer sessions, and other in-class activities. In order to maintain confidentiality, the name of the assessor was not included in the assessment form. The individual mark on class participation (10\%) was determined by taking the average individual score obtained from peer assessment, adding to the lecturer's score, then divide by two to derive the final mark. Two class representatives were appointed to assist the lecturer in computing and compiling the final marks.

At the end of the semester, student reactions to peer and self-assessment were solicited by means of anonymous questionnaires conducted before the students knew the assessment results of the unit in both cycles of research. The questionnaire consisted of 4 closed questions, 2 open questions and 13 statements to which students were asked to respond by indicating their level of agreement. A 5-point category scale was used, with $5=$ strongly agree, $4=$ agree, $3=$ neutral, $2=$ disagree and $1=$ strongly disagree. The questions were derived from other published studies (Brindley \& Scoffield, 1998; Ryan et al., 2007) and based on the author's experience with issues of class participation assessment. Mean for all statement were calculated and percentage was used to display the responses of the closed questions.

\section{Results}

Table 1 presents the mean score of each statements rated by the students. In the sample as a whole, students appear to find the assessment exercise of benefit and their responses were positive on six statements, taking a score above 3.50 as positive. The study corroborates Brindley and Scoffield's study (1998) where students expressed that the practice promotes a sense of ownership, engagement and personal responsibility of the learning experience (mean score 3.82). Moreover, they perceived an increase in personal motivation (3.81) as a result of their active participation in peer assessment. The results also reflected that students fully understood what was expected of them in doing the peer assessments (3.79) and the scoring rubric given was helpful in doing the peer evaluation (3.68). This is not entirely unexpected because the lecturer had spent a large amount of time discussing the process with the students and preparing them for the assessment task.

On the other hand, the results show that the students found it not easy to evaluate their peers. Refer to Figure $1-$ that indicates $70 \%$ of the students disclosed to alter marks as the assessment progressed. Many students did not feel the need to participate more because of peer assessment. The statement "I participated more because I knew my peers were evaluating me" only has a mean score of 3.45 .

In general, the mean score of Semester 1 is higher and more positive than Semester two, even though Semester two students were involved in developing the assessment criteria. It was natural for Semester two students to assign higher score on the statements "I fully understand what was expected of me in doing the peer assessments" and "I found it easy to evaluate my peers on their class participation" due to their involvement in setting the assessment criteria. But their rating on other statements indicated that they are less in favor of the peer assessment exercise. The literature suggests that allowing the students to be involved with the creation of the evaluation criteria may improve student understanding and acceptance of the assigned grades (Dochy et al., 1999). However, the result of this study reflected a slightly different view.

According to Topping et al. (2000), students experienced a sense of socio-emotional discomfort in grading their peers. In this result, only two students stated no pressure in the peer evaluation exercise, $71 \%$ experienced some pressure (see Figure 2).

Figure 3 indicated the main pressure appears to stem from the assessment process as a whole (41.6\%) and class participation (32.5\%). It was interesting to note that only $13 \%$ of the students felt that the pressure came from their peers and another 13\% from tutors. These results supported the findings of Brindley and Scoffield's study (1998).

From the sixty written comments given, seven students reported that they get to know their peers better and paid more attention in noting the class participation of others. One student suggested to include students' photographs would help in assigning peer scores.

\section{Discussion}

Some literature advised that peer assessment of class participation should not be recommended for grading purposes due to the issue of reliability and validity of peer evaluations. The objective of this study was to explore students' opinion of their involvement in grading class participation. The study found that students do not reject 
peer assessment strategy. The author concurs with Gopinath (1999) that the benefits of peer assessment extend beyond the question of reliability of the grade. This issue can be minimized if students are provided with precise rating criteria and asked to rate through an interval scale on the different criteria which capture the essence of class participation.

The traditional belief that "teacher knows best" and holds the reins of power in the assessment process needs to change especially in an Asian learning culture. To develop student autonomy in learning and promote active learning, students have to get involved in the process of setting learning objectives and the process of assessment. Thus in this study, having peer assessment provided an input into lecturer's assessment of class participation served the objective of student involvement. Student involvement in assessment process also tends to increase the transparency of assessment and students' motivation in class. Peer assessment is, therefore, a valuable exercise in self-development and preparation for students' future careers. It certainly helps in building Curtin Graduate Attributes - thinking skills, information skills, communication skills, learning how to learn, and professional skills - among the students.

Peer assessment is not a set prescriptive process, but rather one that may take time to develop and may also change over time depending on the course content, class size, the curriculum, the university culture, and the students themselves. It is suggested that students need to undergo attitudinal changes towards their learning roles and need practice in more self-evaluative role behaviours if peer assessment is to become more acceptable and successful (Brindley and Scoffield, 1998). In this study, students who disliked peer evaluation believed the process was bias and could result in an unfair grade. This was commented on by eight students in their written remarks. Some felt that it was a tedious process and bringing unnecessary pressure to students as peer assessment was rarely practiced consistently in Business School. A student indicated preference using self assessment instead of peer assessment.

It is recommended to introduce self assessment exercise to various types of assignments and business units at Curtin Sarawak, starting with the first year students. This serves to expose the students to different assessment method and develop them into more autonomous learners, and less dependence on the tutor for all the answers. As these students progress in their course, greater experience will be gained in assessment and learning, then peer assessment may become more acceptable and successful, and increase in value.

To conclude, this study shows that students see the value of peer assessment and it improves the learning experience and satisfaction. Students felt connected to each other in class as they paid attention to each other's discussions, took greater ownership of their learning. Peer and self assessment promotes partnership between student and lecturer that is empowering and equal. The outcomes of this study may be of interest to lecturers who wish to introduce self and peer-assessment in higher education. This action research of peer assessment on classroom participation produces useful insights on the practice of peer assessment and sheds light on student attitudes to peer assessment.

\section{Reference List}

Bean, J.C. \& Peterson, D. (1998). Grading Classroom Participation. New Directions For Teaching And Learning. 74(1), 33-40.

Brindley, C. \& Scoffield, S. (1998). Peer Assessment in Undergraduate Programmes. Teaching in Higher Education. 3(1), 79-90.

Boud, D. (1995). Enhancing Learning Through Self Assessment. London. Kagan Page.

Chapnick, A. (2009). "A Participation Rubric," The Teaching Professor. From http://www46.homepage.villanova.edu/john.immerwahr/TP101/lects/participation\%20matrix0001.pdf

Craven III, J.A. \& Hogan, T. (2001). Assessing Student Participation in the Classroom. Science Scope. 25(1), 36-40.

Davis, B.G. (1993). Tools for Teaching. San Francisco: Jossey-Bass.

Dochy, F., Segers, M. \& Sluijsmans, D. (1999). The Use of Self-, Peer and Co-assessment in Higher Education: A Review. Studies in Higher Education. 24(3), 331-350.

Falchikov, N. (2001). Learning Together: Peer Tutoring in Higher Education. London. Routledge Falmer.

Falchikov, N. \& J. Goldfinch. (2000). Student Peer Assessment in Higher Education: A Meta-Analysis Comparing Peer and Teacher Marks. Review of Educational Research. Fall. 70(3), 287-322.

Gopinath, C. (1999). Alternatives to Instructor Assessment of Class Participation. Journal of Education for Business. 75(1), 10-14. 
Maznevski, M. L. (1996). Grading Class Participation. Teaching Concerns. University of Virginia, Spring 1996. From http://trc.virginia.edu/Publications/Teaching_Concerns/Spring_1996/TC_Spring_1996_Maznevski.htm Melvin, K. (1988). Rating Class Participation: The Prof/Peer Method. Teaching of Psychology. 15(3), 137-139. Ryan, G. J., Marshall, L. L., Porter, K. \& Jia, H. (2007). Peer, Professor and Self-evaluation of Class Participation. Active Learning in Higher Education. 8(1), 49-61.

Sadler, P. M. \& Good, E. (2006). The Impact of Self-and Peer-grading on Student Learning. Educational Assessment. 11, 1-31.

Sivan, A. (2000). The Implementation of Peer Assessment: An Action Research Approach. Assessment in Education. 7(2), 193-213.

Stefani, L. A. J. (1994). Peer, Self and Tutor Assessment: Relative Reliabilities. Assessment and Evaluation in Higher Education. 19(1), 69-75.

Topping, K. (2009). Peer Assessment. Theory Into Practice. 48(1), $20-27$.

Topping, K. (1998). Peer Assessment Between Students in Colleges and Universities. Review of Educational Research. 68(3), $249-276$.

Topping, K. J., Smith, E. F., Swanson, I. \& Elliot, A. (2000). Formative Peer Assessment of Academic Writing between Postgraduate Students. Assessment \& Evaluation in Higher Education. 25(2), 149-170.

Van Den Berg, I. (2006). Peer Assessment in University Teaching: Evaluating Seven Course Designs. Assessment \& Evaluation in Higher Education. 31 (1), 19.

Table 1. Students' View on Peer Assessment $(\mathrm{n}=77)$

\begin{tabular}{|c|c|c|c|}
\hline Statement & $\begin{array}{l}\text { Overall } \\
\text { Mean }\end{array}$ & $\begin{array}{c}\text { Semester } 1 \\
(n=42)\end{array}$ & $\begin{array}{c}\text { Semester } 2 \\
(n=35)\end{array}$ \\
\hline & $(n=77)$ & \multicolumn{2}{|c|}{ Mean } \\
\hline $\begin{array}{l}\text { Peer assessment promotes a sense of ownership, engagement, and personal } \\
\text { responsibility in my learning experience. }\end{array}$ & 3.82 & 3.90 & 3.71 \\
\hline $\begin{array}{l}\text { Involvement in the assessment process increases my personal motivation in } \\
\text { the class. }\end{array}$ & 3.81 & 3.93 & 3.66 \\
\hline I fully understand what was expected of me in doing the peer assessments. & 3.79 & 3.71 & 3.89 \\
\hline $\begin{array}{l}\text { Peer assessment promotes self-evaluation and develops my critical thinking } \\
\text { and other professional skills. }\end{array}$ & 3.69 & 3.83 & 3.51 \\
\hline The assessment form given is helpful in doing the peer assessments. & 3.68 & 3.62 & 3.74 \\
\hline $\begin{array}{l}\text { Peer assessment marks should be taken into consideration to compute the } \\
\text { overall participation score. }\end{array}$ & 3.61 & 3.74 & 3.46 \\
\hline $\begin{array}{l}\text { I feel that peer evaluation was fair in helping to determine my class } \\
\text { participation grade. }\end{array}$ & 3.49 & 3.60 & 3.37 \\
\hline I would recommend using peer evaluation grades in the future. & 3.45 & 3.60 & 3.29 \\
\hline I participated more because I knew my peers were evaluating me. & 3.45 & 3.48 & 3.43 \\
\hline I do not feel sufficiently capable to mark other students' participation level. & 3.23 & 3.29 & 3.17 \\
\hline I feel intimidated by the whole process. & 3.14 & 3.12 & 3.17 \\
\hline Assessment should be the sole responsibility of tutors. & 3.08 & 2.90 & 3.29 \\
\hline I found it easy to evaluate my peers on their class participation. & 2.94 & 2.74 & 3.17 \\
\hline
\end{tabular}

Note: Scale: 1 - 5, 1 = Strongly Disagree, 2 = Disagree, $3=$ Neutral, 4 = Agree, $5=$ Strongly Agree 


\section{As the experience progressed, did you feel the need to alter your initial} assessments?

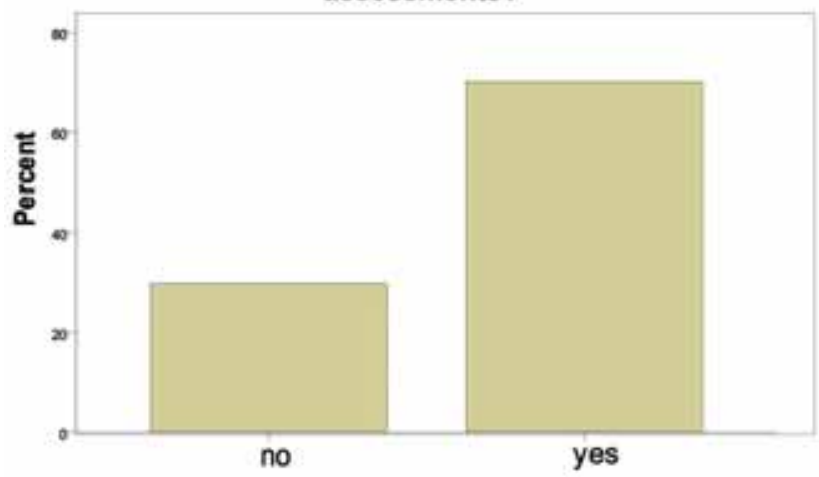

Figure 1. Alter mark

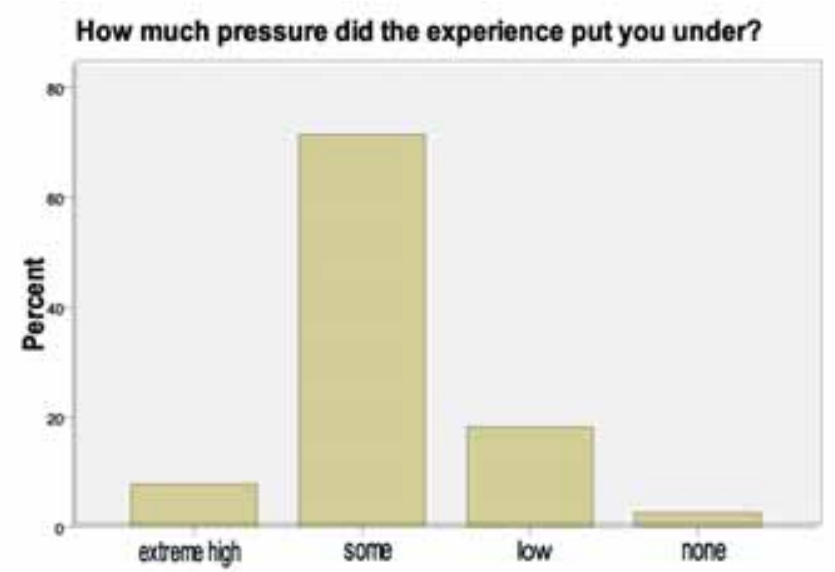

Figure 2. Amount of pressure

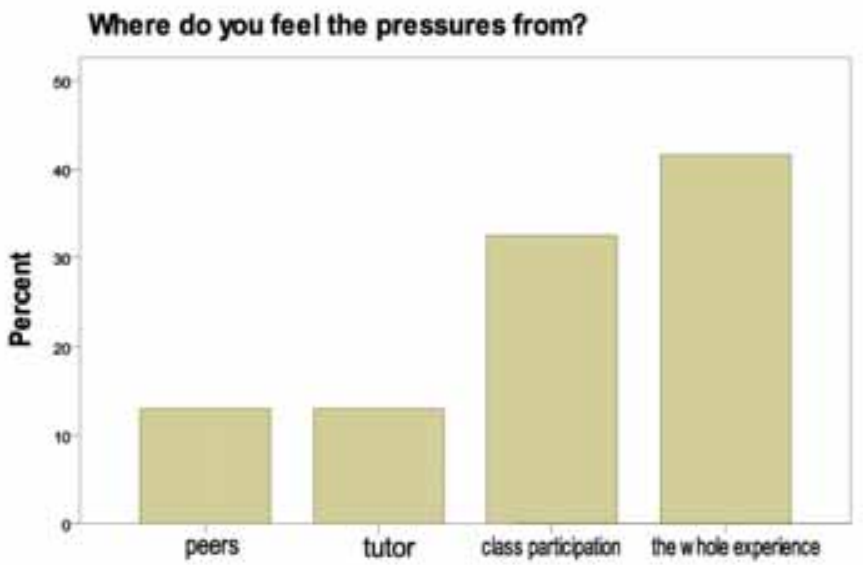

Figure 3. Source of pressure 